of much of this in a later chapter on Hagemann factor seems to be unnecessary.

There have been so many reviews on prostaglandins in the past year or so that I was pleased to see only one modest chapter on this subject. But with the increasing knowledge of the importance of products of arachidonic acid metabolism other than prostaglandins, it seems unfortunate that this chapter did not include more information about thromboxane and the lipoxygenase products including SRS-A.

The book includes a very comprehensive chapter on complement and chemotaxis in which old and new methodologies in this complicated field are explained and compared.

In addition to discussions on mediators which might affect intracellular activities, there are two accounts of some cellular components which might be affected and which might play a role in the tissue damage which accompanies chronic inflammatory conditions. These are the lysosomal enzymes of which we are told there are more than $\mathbf{4 0}$ which are mostly hydrolytic and the acid cathepsins. They might well play a role not only in causing tissue damage but also in the formation of biologically active degradation products.
But in spite of an enormous amount of research in this field, the extent of the involvement of these enzymes is not known. However, the discussions include an interesting description of the control mechanisms involved which might give a pointer to the direction that future work should take.

Volume 1 concludes with three fascinating chapters about factors controlling the growth of cells. Many of us who have become familiar with the mediators of the vascular changes and cell migration and activation in inflammation are not so familiar with growth factors and their inhibitors. The significance of macrophage growth factor in biology, for example, is just beginning to emerge. The future will reveal how important are the factors controlling differentiated cell populations at sites of inflammation and their role in inflammation and tissue repair.

Not only is the proliferation of inflammatory cells a significant aspect of inflammation but the proliferation of endothelial cells in growing blood vessels is also important, particularly in tissue repair. The editors decided to cover this aspect with a review on tumour angiogenesis which I personally found exciting and stimulating.

Finally we are treated to another fascinating account, this time about chalones, the tissue-specific inhibitors of cell proliferation. The chapter starts with the story of the early theoretical considerations and the early experimental evidence for the existence of chalones, and goes on to describe the arguments of mitotic stimulators versus mitotic inhibitors. A final glimpse into the future suggests the possibility of inhibiting the mast cell proliferation in Urticaria pigmentosa with a mast cell chalone.

There is no doubt that this first volume of the Handbook is a valuable addition to the literature on inflammation. It is a pity that the book, superficially well produced, has suffered from deplorable copy-editing and proof-reading - over 200 typographical and grammatical errors, and discrepancies in the references, have been noted in just two chapters. A list of these has been sent to the publishers, who will hopefully take greater care over subsequent volumes.

G. P. Lewis is Professor of Pharmacology in the Institute of Basic Medical Sciences, Royal College of Surgeons, London, UK.

\section{Science from the Serengeti}

\section{Hans Kruuk}

Serengeti: Dynamics of an Ecosystem. Edited by A.R.E. Sinclair and M. NortonGriffiths. Pp.389. (University of Chicago Press: Chicago and London, 1980.) $\$ 28.50, £ 17.10$.

THE STREAM of papers emanating from the once so active Serengeti Research Institute has dwindled over the past decade, and the Institute is now only a shadow of its former self. The large concerted effort by scientists from many disciplines to provide an ecological basis to the management of this huge ecosystem in Tanzania has virtually stopped. What is the result of all this effort? Serenget $i$ is a sample of the diversity of output of the Serengeti Research Institute, with contributions from a dozen of its former scientists; the book is an attempt to take stock, and to evaluate some of the research in terms of conservation and management. It is clearly focused on the phenomenon for which the Serengeti is justly famous, the vast population of migratory ungulates.

Of the 13 chapters, three by A.R.E. Sinclair describe the Serengeti background, the history and the migrations of its animal populations; the interactions between the most important migratory and resident ungulates and the vegetation are studied in detail in a further four chapters by S.J. MacNaughton, P.J. Jarman and Sinclair, L. Maddock, and M. NortonGriffiths. C.J. Pennycuick analyses the cost of locomotion to the migrants, $\mathbf{R}$. Hilborn and Sinclair describe simulation studies of the Serengeti populations, and P.J. and M.V. Jarman compare ungulate social organizations. Three chapters, one by B.C.R. Bertram, one by J.P. Hanby and J.D. Bygott, and one by D.C. Houston look at the large predators and scavengers, their social systems, population changes and adaptations to the herbivore migrations.

The book is more a collection of distinct individual contributions than a united evaluation. However some of these contributions are outstanding; I was particularly struck by MacNaughton's beautiful experimental approach to the grazing relationships. Norton-Griffiths' clear analysis of the relation between animal populations and movements, climate, fire and other factors in this huge ecosystem should be an example to many other studies in this field. The predator chapters give a summary of much of the work that has been done on the Serengeti carnivores, and they indicate once again the complicated consequences for the carnivores' social organization of a rapidly increasing prey population. At the end of the book there is a useful list of over 300 references to the scientific publications of the Research Institute.

In general, the quality of all the chapters is good, and the book is full of fascinating observations which more than overshadow its shortcomings. One feels the absence of a chapter on the botanical and soil studies carried out in the Serengeti - everything is seen through zoologists' eyes. The two introductory chapters with their categoric statements fall somewhere between reviews and new contributions, without doing full justice to either of these functions. Scientific modesty would be served if it were pointed out that present population levels of ungulates are well above anything that was predicted as 'equilibrium' only a few years ago, thus indicating some of the limitations of the work of ecologists in such an ecosystem, even when the most elegant predictive models are used. And clearly it is prudent not to attempt to explain these population increases only in terms of the eradication of rinderpest in the early 1960 s, since non-vulnerable species also increased - a fact conveniently forgotten in some of the chapters.

These are relatively minor grumbles, however, as are the irritation of the printing errors and the unaccredited photographs in one batch in the middle of the book which are not related to the text. What I missed most of all was a final chapter by the editors in which they could have pulled the strings together instead of leaving the papers as separate entities.

Despite all this, the book stands as an important monument to the efforts of the Serengeti Research Institute, and $I$ have no doubt that it will be a work of reference for many studies elsewhere. I hope that before long the Institute itself will again be in a position to make full use of it.

Hans Kruuk is a Principal Scientific Officer at the Institute of Terrestrial Ecology, Banchory, $U K$. 